\title{
Clinical Management of Infant Anaphylaxis
}

\section{Annette Carlisle \\ Jay Lieberman}

Department of Pediatrics, Division of Pediatric Pulmonary, Sleep, Allergy \& Immunology, The University of Tennessee Health Science Center, Le Bonheur Children's Hospital, Memphis, TN, USA
Correspondence: Annette Carlisle Department of Pediatrics, Division of Pediatric Pulmonary, Sleep, Allergy \& Immunology, The University of Tennessee Health Science Center/Le Bonheur Children's Hospital, Faculty Office Building 49 N. Dunlap \#217,Memphis, TN, 38103, USA

Tel + I 90I-287-5590

$\mathrm{Fax}+1$ 90I-287-7450

Email acarlis3@uthsc.edu

\begin{abstract}
Anaphylaxis is a condition that is likely increasing in prevalence and commonly treated by allergists as well as other first responders and emergency room providers. Although a relatively rare event, anaphylaxis can occur in infants, with the most common cause attributed to foods. Infant anaphylaxis can present with unique diagnostic challenges and treatment considerations. While infants can present with classic signs and symptoms of anaphylaxis (eg, urticaria, angioedema, dyspnea, wheeze, and vomiting) they can also present with non-classical signs. Non-classical signs of infant anaphylaxis can include ear pulling, tongue thrusting, fussiness, and increase clinginess to the caregiver. These non-classic signs of infant anaphylaxis can often mimic normal infant behavior further complicating the diagnosis. Additionally, when treating infant anaphylaxis, there are special considerations regarding the use of epinephrine. These include determining appropriate needle length, dosages appropriate to administer depending on the weight of the infant, and the availability of different epinephrine auto-injectors. In this article, we aim to review the clinical management of infant anaphylaxis including diagnosis, recognition, treatment, strategies for follow-up and special considerations regarding epinephrine administration in this demographics.
\end{abstract}

Keywords: infant anaphylaxis, epinephrine

\section{Introduction}

Anaphylaxis is a common condition with an estimated prevalence of at least $1.6 \%$ in the United States and this is likely increasing. ${ }^{1}$ Despite anaphylaxis being a cornerstone of allergy training, the diagnosis can often be difficult and there can often be lack of agreement. ${ }^{2}$ And while all major guidelines agree that epinephrine is the treatment of choice, there continue to be barriers to its widespread use. ${ }^{3}$ Unfortunately, diagnosis and management of infant anaphylaxis can present even more unique challenges than in older ages due to difficult clinical presentation and unique challenges to epinephrine administration (Figure 1). Thus, it is important for providers to be well versed in the management of infant anaphylaxis including proper diagnosis, recognition, acute management, longterm follow up and special considerations about epinephrine. We aim to review the current literature regarding clinical management of infant anaphylaxis. We completed a comprehensive PubMed search using the key search terms "clinical management of infant anaphylaxis." We also searched using synonyms for infants (toddler, baby, age up to three years old), anaphylaxis (allergic reaction, epinephrine, epinephrine auto-injector use, anaphylactic shock, hypersensitivity reaction, pediatric anaphylaxis), and clinical management (medical management). The search produced approximately 300 articles. Full texts were screened with emphasis placed on high-quality studies (reviews, consensus statements). Additional references were 


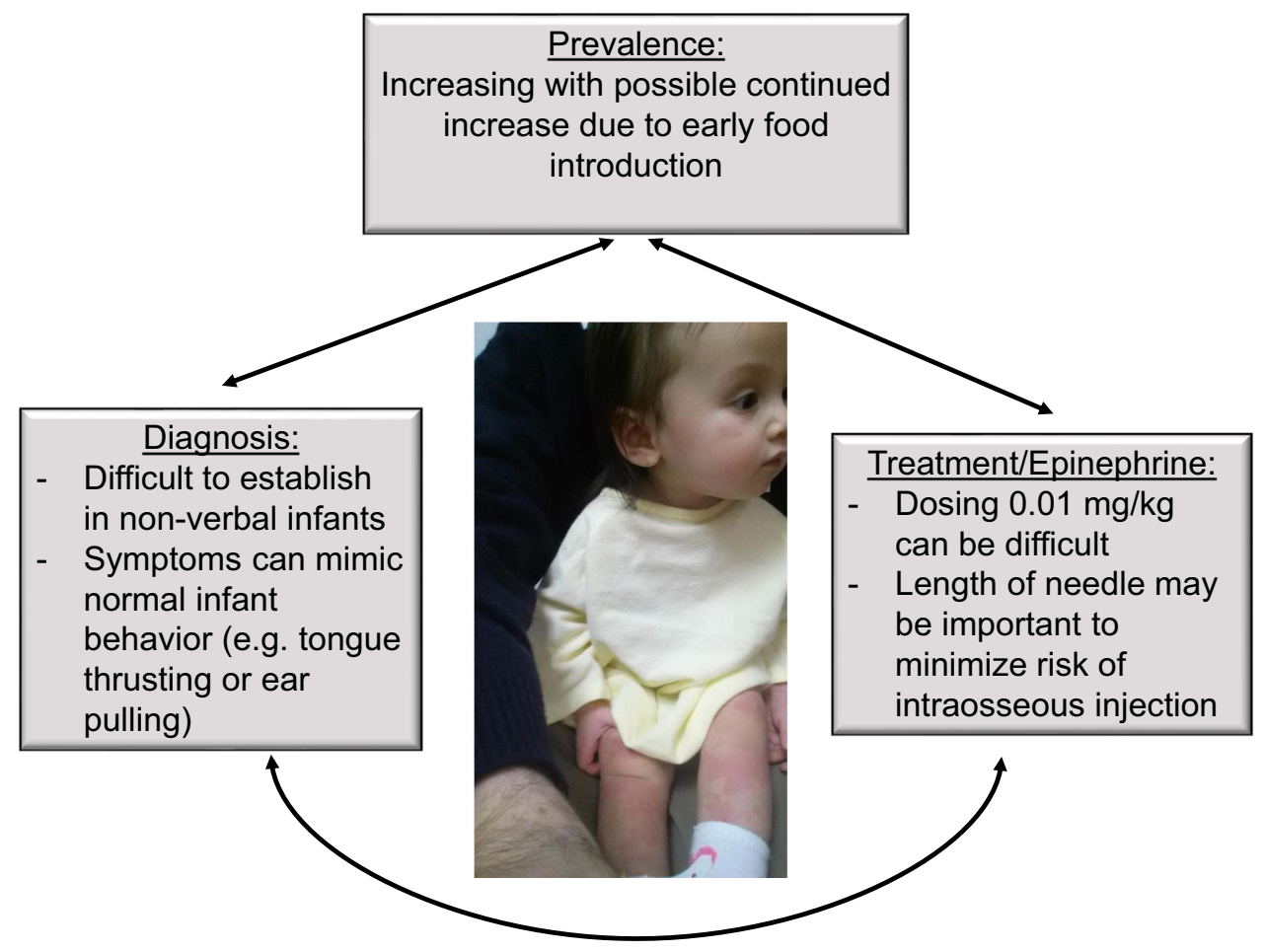

Figure I Review of unique aspects regarding management of infant anaphylaxis.

added after cross-referencing initial studies. For use in this review, we consider infants $0-12$ months but also recognize much of this information is pertinent in patients up to 36 months as per the recently published expert consensus on treatment of infant anaphylaxis. ${ }^{4}$

\section{Prevalence}

The prevalence of infant anaphylaxis is largely unknown but overall it is rare. For example, in the European Anaphylaxis Registry, infants $<1$ year of age only accounted for 18 out of a total of $1970(0.9 \%)$ cases in an anaphylaxis cohort of children and adolescents. ${ }^{5}$ This is less than would be expected by natural distribution of age. Data suggest though that the number of cases is increasing similar to known increases in food allergy prevalence over recent years. ${ }^{6-8}$ Between 2007 and 2012, food induced anaphylaxis prevalence increased $50 \%$ in ages 6 months to 18 years. ${ }^{9}$ A review of food-induced anaphylaxis cases at two Boston children's hospitals found $29 \%$ of patients presenting were less than two years old. ${ }^{10}$ Dyer et al noted between 2008 and 2012 there was an annual increase of $27 \%$ of food-induced anaphylaxis cases in children ages $0-4 .^{11}$ Thus, given the increasing number of food-induced anaphylaxis cases in all ages, it is possible that the number of infant anaphylaxis cases will simply mirror this increase. However, with new data showing the benefit of early introduction of allergenic foods on the overall prevalence of food allergy; ${ }^{12}$ it is reasonable to expect an increase in food-induced allergic reactions in infants who would not have been fed the food in years past based on former recommendations. ${ }^{13}$ Thus, it is very likely that over time, more and more infants will be fed allergenic foods, which should decrease overall food allergy prevalence, but may also in time lead to more frequent infant allergic reactions.

\section{Diagnosis}

Although an infant-specific diagnostic algorithm for anaphylaxis has not been developed, the recently published expert panel consensus by Greenhawt et al suggests using the current NIAID/FAAN definition to define potential cases. ${ }^{4,14}$ According to the NIAID/FAAN criteria, anaphylaxis is highly likely when any one of the three criteria are met: 1) Acute onset of illness (minutes to several hours) with involvement of the skin, mucosal tissue, or both and at least one of the following: respiratory compromise or reduced blood pressure. 2) Two or more of the following that occur rapidly after exposure to a likely allergen for 
that patient (minutes to hours): involvement of the skinmucosal tissue, respiratory compromise, reduced blood pressure or associated symptoms, or persistent vomiting. 3) reduced blood pressure after exposure to a known allergen for that patient (minutes to hours) defined as low systolic BP based on age or greater than $30 \%$ decrease in systolic BP or systolic $<90 \mathrm{mmHg}$ or greater than $30 \%$ decrease from baseline as adults. ${ }^{14}$

Infant anaphylaxis can be triggered by a variety of agents but most often is due to foods. Specifically, cow's milk, egg, peanut, and tree nuts have been recognized as the most common culprits worldwide. ${ }^{4,5,15-17}$ Less common agents implicated include drugs (antibiotics, antipyretics, neuromuscular blockers, etc), vaccines, insect stings, natural rubber latex, and topical agents; however, these are very rare triggers in infants. ${ }^{18,19}$ Idiopathic anaphylaxis has even been reported in infants, but once again, this is

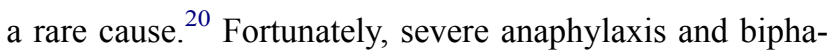
sic reactions are less commonly reported. ${ }^{4}$ Co-morbidities increasing the risk of severe infant anaphylaxis are not well defined in infants although it has been suggested that co-morbid conditions including croup, bronchiolitis, asthma, and atopic dermatitis could potentially increase risk. $^{4,18}$ Known peanut and tree nut allergy have also been found to be risk factors for severe reactions. ${ }^{17,21}$ Additionally, it has been postulated that co-factors in infant anaphylaxis could be similar as in other age groups including fever, upper respiratory tract infection, and emotional stress. However, no infant-specific studies support what co-morbidities or co-factors play a role and further research is needed in these areas. ${ }^{22-24}$

Recognition of infant anaphylaxis resembles recognition of anaphylaxis in other age groups. In the appropriate clinical context, anaphylaxis will most likely include cutaneous (generalized urticaria, flushing, angioedema), gastrointestinal (persistent vomiting), cardiovascular (tachycardia, hypotension), respiratory (cough, wheeze, stridor) and/or behavioral changes. ${ }^{18}$ In infants specifically, several studies have demonstrated cutaneous symptoms are the most common followed by gastrointestinal and respiratory symptoms; cardiovascular symptoms (eg, hypotension) are rarely reported. 5,10,25 Furthermore, hypotension may be a late sign of infant anaphylaxis compared to adults while tachycardia may be an early indicator of cardiovascular involvement in infants, although this may represent common routes of exposure of the antigen in these age groups (ie, venom stings and parenteral medications are likely to lead to early hypotension, and this is simply seen more often in adults than infant).

Diagnostic challenges can often arise as infants are non-verbal and allergic symptoms can overlap normal infant behavior or symptoms that overlap with other pediatric conditions (Table 1). For example, infants cannot verbally describe several symptoms associated with anaphylaxis such as difficulty breathing, pruritus, throat closure sensation, feeling faint, or sense of impending doom. Furthermore, several infant behaviors including clinging to the caregiver, cessation of playing, crying, spitting up/ regurgitation after foods, increased secretions, loose stools, sleepiness/drowsiness after feeds, flushing with fever or crying spells, scratching, and irritability can all be normal behaviors, leading to misdiagnosis of anaphylaxis if inappropriately interpreted depending on the clin-

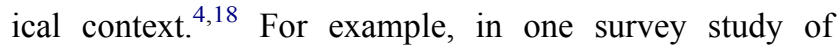
caregivers, infants who had anaphylaxis had reported signs such as eye rubbing in about $40 \%$ of cases and ear pulling in about $16 \%$ of cases. ${ }^{26}$ In addition to normal infant behavior or anaphylaxis, other differentials such as the one published by Simons \& Sampson must be considered. ${ }^{18}$ These include skin manifestations related to underlying viral exanthem or hereditary angioedema, congenital respiratory anomalies, breath holding spells, gastrointestinal tract obstruction, gastrointestinal anatomic abnormalities such as pyloric stenosis or malrotation, food protein-induced enterocolitis, various forms of shock not due to anaphylaxis, central nervous system issues such as seizure disorder, other infectious-disease-

Table I Signs of Infant Anaphylaxis $4,18,26$

\begin{tabular}{|l|l|}
\hline \multicolumn{1}{|c|}{ Classic Symptoms } & \multicolumn{1}{|c|}{ Non-Classic Symptoms } \\
\hline $\begin{array}{l}\text { Skin: hives, rashes, } \\
\text { itching, angioedema }\end{array}$ & $\begin{array}{l}\text { Skin: eye rubbing, eye itching, ear } \\
\text { scratching, tongue thrusting, tongue } \\
\text { pulling, repetitive lip licking or licking of } \\
\text { hands }\end{array}$ \\
\hline $\begin{array}{l}\text { Gl: vomiting, diarrhea, } \\
\text { abdominal pain }\end{array}$ & $\begin{array}{l}\text { Gl: spitting up, back arching, bringing knees } \\
\text { to chest, hiccups }\end{array}$ \\
\hline $\begin{array}{l}\text { Respiratory: cough, } \\
\text { wheeze, tachypnea }\end{array}$ & $\begin{array}{l}\text { Respiratory: hoarse voice/cry, putting } \\
\text { fingers in ears, ear pulling }\end{array}$ \\
\hline $\begin{array}{l}\text { CV: hypotension, } \\
\text { fainting }\end{array}$ & CV: skin mottling \\
\hline & $\begin{array}{l}\text { Neuro: crankiness, inconsolable crying, } \\
\text { withdrawn/clingy }\end{array}$ \\
\hline
\end{tabular}

Note: Data from Greenhawt et al ${ }^{4}$, Simons et al ${ }^{18}$, Pistiner et al ${ }^{26}$. 
related presentations, ingestions, as well as others. ${ }^{18}$ When diagnosing infant anaphylaxis, it is crucial to obtain a thorough history in order to tease out the subtleties that would suggest true anaphylaxis versus another cause.

Work up of infant anaphylaxis in the acute setting should parallel previously published guidelines focusing on acute treatment as well as identification of a possible allergic trigger. ${ }^{27,28}$ Prompt evaluation including obtaining vital signs and history noting potential triggers should be obtained. While obtaining the history, it is critical to pay attention to the timing of symptoms as IgE-mediated reactions occur within minutes and rarely after two hours. Unfortunately, there is no biomarker with high sensitivity and specificity for anaphylaxis, especially in food allergic reactions, which are the most common in infants. ${ }^{4}$ Within two to four hours of the inciting incident, mast cell tryptase can be considered. Mast cell tryptase must be obtained within this time frame as outside of this window the value is mostly reflective of the resting burden of mast cells and not necessarily clinically useful unless underlying mast cell disease. ${ }^{29}$ Additionally, with food induced anaphylaxis mast cell tryptase may not always be elevated. ${ }^{22}$ Thus, while a highly elevated tryptase in the acute setting can be helpful, a low tryptase may not necessarily exclude anaphylaxis particularly with foods. Once the patient is stable for discharge, caregivers should be instructed to avoid the possible causative trigger, prescribed an epinephrine auto-injector and instructed on indications and how to administer given that most cases of infant anaphylaxis as well as episodes of recurrent anaphylaxis occur at home. The possibility of recurrent anaphylaxis and known risk factors should also be discussed with families. Patients follow-up with an allergist for further work-up is also recommended. ${ }^{28}$ Unfortunately, this may not always be frequently done. For example, Wright et al showed that at one pediatric hospital that has an associated allergy division, only $30 \%$ of confirmed pediatric anaphylaxis cases in their ED were referred to an allergist, and only $10 \%$ actually saw the allergist. ${ }^{30}$

In the outpatient setting after the initial reaction, obtaining a history remains critically important. During the history, the time course as well as potential triggers and co-factors should be documented. Based on the history, work-up in the outpatient setting can include skin prick testing or if skin prick testing is unavailable serum IgE testing can be completed to detect sensitization to potential triggers. Testing should be dictated by history, and the authors do not recommend performing food panel testing. If the initial testing was negative but strong clinical suspicion of anaphylaxis exists, one can consider repeating the testing for suspected triggers in four to six weeks with continued avoidance until repeat testing. ${ }^{18}$ This is due to the fact it can take four to six weeks from the initial mast cell degranulation for skin testing to be positive. Once allergic triggers are identified based on history and/or testing, families should be educated on avoidance and proper use of the epinephrine auto-injector. ${ }^{4}$

\section{Treatment}

Treatment of infant anaphylaxis, as with anaphylaxis in any age group, should begin promptly with the administration of epinephrine. Unfortunately, infants may be at an even greater risk than other ages for delayed epinephrine administration due ambiguity in infant symptoms and their mimicking normal infant behavior. ${ }^{31}$ Furthermore, several studies have shown that there is delayed epinephrine use in both the healthcare and home setting, and thus all parties should be comfortable with administering epinephrine for improved outcomes. ${ }^{3,30,32}$ In the home setting, it has been reported that parents are often fearful to give epinephrine or were unsure whether or not epinephrine should be administered. ${ }^{30,33}$ If an infant is at home, where anaphylaxis is most likely to occur, and there is concern for anaphylaxis, it is important that caregivers are educated on the proper management including being comfortable with epinephrine administration. Additional treatment strategies include removal of any suspected trigger, rapid assessment of airway, breathing, and circulation as well as prompt administration of epinephrine using an autoinjector. ${ }^{18}$ Caregivers should also understand they can give multiple doses every three to five minutes if needed and understand the importance of either calling 911 or going to the emergency department for further evaluation, treatment, and monitoring in case of a severe reaction.

For management in the health care setting, many of the same steps apply (Figure 2). ${ }^{18}$ Initially, remove any suspected trigger. Rapidly assess airway, breathing, circulation, skin and record patient's weight. The infant should be placed in a supine or semi-reclining position in the caregiver's arms. In infants with suspected anaphylaxis or severe allergic reaction, inject epinephrine intramuscularly at a dose of $0.01 \mathrm{mg} / \mathrm{kg}$ or use an epinephrine auto-injector $(0.15 \mathrm{mg}$ or $0.1 \mathrm{mg})$ in the community setting (dosing discussed further below). The auto-injectors can be used in the health care setting as well as some institutions may find them more convenient than using epinephrine vials 


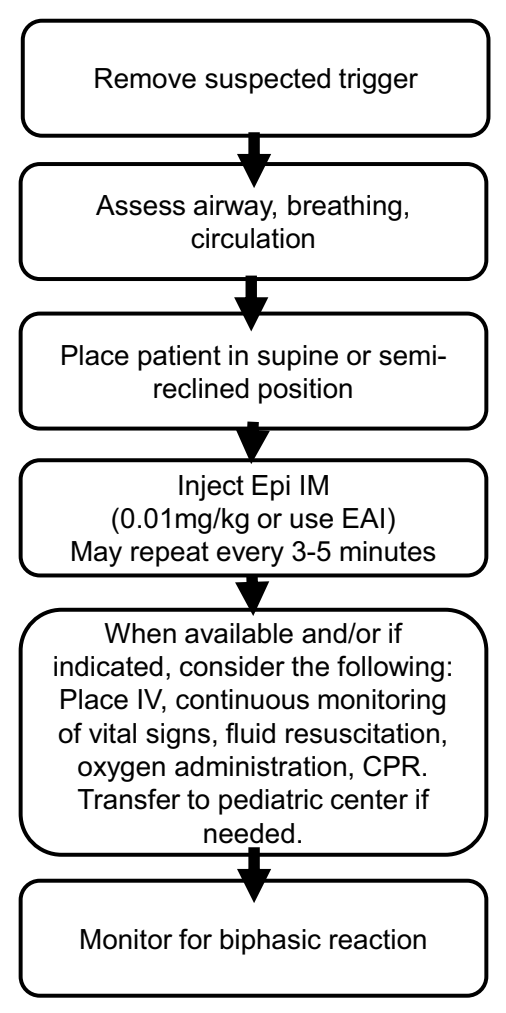

Figure 2 Treatment of infant anaphylaxis. Note: Data from Simons et al. ${ }^{18}$

and syringes which require using filter needles and drawing up exact amounts of drug. Typically, however, epinephrine vials and syringes are cheaper and allow for more accurate weight-based dosing. When needed, establish IV access and start fluid resuscitation giving a dose of 10 $20 \mathrm{~mL} / \mathrm{kg}$ of normal saline over 5 to $10 \mathrm{~min}$. Additionally, high-flow supplemental oxygen $(8-10 \mathrm{~L} / \mathrm{m})$ can be administered through an infant face-mask. When available, the infant should be hooked up to a continuous monitor for respiratory rate, heart rate, oxygen saturations, and blood pressure with an appropriately sized cuff. ${ }^{18}$ If indicated, start cardiopulmonary resuscitation per pediatric advance life support guidelines. This includes giving thirty compressions at a rate of 100-120/minute compressing onethird the depth of the chest allowing complete recoil. ${ }^{34}$ Epinephrine can be given every three to five minutes as needed as this is first-line treatment. If infants with refractory anaphylaxis requiring multiple doses of epinephrine or with significant cardiovascular or respiratory involvement, an epinephrine infusion may be started. There is some debate over the utility of additional antihistamines, corticosteroids, or B-agonists and can be given if deemed fit; however, these are not first-line agents and will not rapidly reverse laryngeal edema, bronchospasm, or hypotension. If an infant does not respond to initial anaphylaxis treatment, the infant should be transferred to a pediatric emergency medicine team equipped in skilled airway, ventilation, and optimal shock management. Once the infant is stabilized, although rare, the infant should be monitored for possible biphasic reaction. ${ }^{18}$

Epinephrine is well tolerated in any age including infants and has a reassuring safety profile. The mechanism of action of epinephrine for use in treatment of anaphylaxis is that it works as a sympathomimetic agent increasing bronchodilation, inotropy/chronotropy, vasoconstriction, and decreasing mucosal edema. ${ }^{35}$ Thus, it is effective in reversing laryngeal edema, hypotension, and bronchoconstriction and downregulates mediators of inflammation. ${ }^{35}$ Epinephrine can be given as either an injection drawn up from an ampule or using an epinephrine auto-injector. The recommended epinephrine dose is $0.01 \mathrm{mg} / \mathrm{kg}$ ( $\max 0.3-0.5 \mathrm{mg}$ ). The epinephrine autoinjectors approved by the Food and Drug administration currently available include $0.3 \mathrm{mg}, 0.15 \mathrm{mg}$, and $0.1 \mathrm{mg}$ dosages. ${ }^{36}$ Both $0.15 \mathrm{mg}$ and $0.3 \mathrm{mg}$ auto-injectors have $1 / 2$ inch $(14.7 \mathrm{~mm})$ needles. The estimated exposed needle length of the $0.1 \mathrm{mg}$ is 0.29 inches $(7.4 \mathrm{~mm}){ }^{36}$

Prior to having the $0.1 \mathrm{mg}$ autoinjector, there were two concerns with using the $0.15 \mathrm{mg}$ autoinjectors in infants: 1) infants could receive an intraosseous injection when using the $14.7 \mathrm{~mm}$ needle length devices and 2) infants could receive a supratherapeutic epinephrine dose and this could lead to adverse events. ${ }^{37}$ In a series of reports using ultrasound or MRI, Kim and Dreborg suggested that several infants (estimated $43 \%$ in one study) would receive an intraosseous injection when using the available $0.15 \mathrm{mg}$ devices. ${ }^{38-40}$ Substituting the $0.1 \mathrm{mg}$ device in these studies mitigated this risk. One must understand that these studies simulated the experience and true intraosseous injection has never been shown and true risk is not known. Therefore, based on needle length, it is reasonable to prescribe the $0.1 \mathrm{mg}$ to infants when available, but the $0.15 \mathrm{mg}$ device can still be used.

Regarding the concern of supratherapeutic dosing, to the authors' knowledge, there are no known reports of adverse cardiovascular outcomes of overdosing with epinephrine in infants. In one succinct review on this topic, Brown simulated percent of optimal dose of epinephrine for weight using the various devices. ${ }^{36}$ While subjects under $10 \mathrm{~kg}$ would receive at least $150 \%$ of the recommended dose $(0.1 \mathrm{mg} / \mathrm{kg})$, and this reaches $200 \%$ at $7.5 \mathrm{~kg}$, one must realize that once the infant is $>10 \mathrm{~kg}$, the clinician risks underdosing epinephrine if 
the infant is prescribed the $0.1 \mathrm{mg}$ device. In fact, based on current CDC growth curves, over $25 \%$ of 6 -month-old infants would be expected to be over $10 \mathrm{~kg}$, and thus even at 6 months, the clinician may underdose many children with the $0.1 \mathrm{mg}$ device. Thus, when prescribing epinephrine autoinjectors in infants, clinicians must weigh the risks and benefits of which epinephrine device to prescribe and take each infant individually.

Finally, in addition to the above needle length and dose concerns, there is a risk of laceration due to using a long needle and jerking of the extremities by the patient. This risk is probably greater in older children who may be harder to hold still for an injection but exists for infants as well. There are holding techniques suggested, and it is important for clinicians to instruct parents and caregivers to make sure the infant is securely positioned with the leg held tight prior to injection. ${ }^{36}$

Periodic follow-up with an allergist is necessary for infants that have experienced anaphylaxis. The goal of longterm follow-up is to reassess previous allergic triggers/evaluate potential resolution, discuss any new allergic triggers, and discuss any barriers to appropriate treatment. Evaluating potential resolution can be followed by measuring serial skin prick or serum-specific IgE testing to specific triggers followed by diagnostic challenges if deemed warranted. Additionally, the epinephrine auto-injector should be adjusted based on patient's weight. At each visit, continued education should be provided including how to properly avoid allergic triggers and how to administer epinephrine auto-injector if needed. It is also of benefit to review and provide families with a written anaphylaxis action plan. ${ }^{41,42}$

\section{Future Directions}

Although more information geared specifically towards infants has been published over the years, further research is still needed. Future directions include consideration of newer infant-specific diagnostic criteria as more data become available as well as more studies defining likely relevant comorbidities and co-factors in this population. Additionally, using a more systematic way of analyzing these cases such as using multi-institutional studies would be helpful.

Given the likely increasing prevalence, infant anaphylaxis will be encountered. Thus, it is important to understand how to define, recognize, and treat infant anaphylaxis as outlined in this article.

\section{Acknowledgment}

The authors would like to thank Tamara Nelson, MLIS, EdS, AHIP for her contributions to this article.

\section{Funding}

No funding was received for this project.

\section{Disclosure}

Annette Carlisle has no conflicts of interests to report.

Jay Lieberman reports the following COI: Research support (money to institution) - Regeneron, DBV technologies, Aimmune; Advisory Board Member (honorarium) DBV technologies.

\section{References}

1. Wood RA, Camargo CA Jr, Lieberman P, et al. Anaphylaxis in America: the prevalence and characteristics of anaphylaxis in the United States. J Allergy Clin Immunol. 2014;133(2):461-467. doi:10.1016/j.jaci.2013.08.016

2. Lieberman JA, Lieberman P, Wang J. Allergists' opinions on anaphylaxis and epinephrine administration - a case-based survey. J Allergy Clin Immunol Pract. 2018;6(3):1075-1077.e1. doi:10.1016/j. jaip.2017.11.031

3. Lieberman J, Wang J. Epinephrine in anaphylaxis: too little, too late. Curr Opin Allergy Clin Immunol. 2020;20(5):452-458.

4. Greenhawt M, Gupta RS, Meadows JA, et al. Guiding principles for the recognition, diagnosis, and management of infants with anaphylaxis: an expert panel consensus. J Allergy Clin Immunol Pract. 2019;7(4):1148-1156.e5. doi:10.1016/j.jaip.2018.10.052

5. Grabenhenrich LB, Dölle S, Moneret-Vautrin A, et al. Anaphylaxis in children and adolescents: the European Anaphylaxis Registry. J Allergy Clin Immunol. 2016;137(4):1128-1137.e1. doi:10.1016/j. jaci.2015.11.015

6. Turner PJ, Gowland MH, Sharma V, et al. Increase in anaphylaxis-related hospitalizations but no increase in fatalities: an analysis of United Kingdom national anaphylaxis data, 1992-2012. J Allergy Clin Immunol. 2015;135(4):956-963 e1. doi:10.1016/j. jaci.2014.10.021

7. Ross MP, Ferguson M, Street D, Klontz K, Schroeder T, Luccioli S. Analysis of food-allergic and anaphylactic events in the National Electronic Injury Surveillance System. J Allergy Clin Immunol. 2008;121(1):166-171. doi:10.1016/j.jaci.2007.10.012

8. Mullins RJ, Dear KB, Tang ML. Time trends in Australian hospital anaphylaxis admissions in 1998-1999 to 2011-2012. J Allergy Clin Immunol. 2015;136(2):367-375. doi:10.1016/j.jaci.2015.05.009

9. Parlaman JP, Oron AP, Uspal NG, DeJong KN, Tieder JS. Emergency and hospital care for food-related anaphylaxis in children. Hosp Pediatr. 2016;6(5):269-274. doi:10.1542/hpeds.2015-0153

10. Rudders SA, Banerji A, Clark S, Camargo CA Jr. Age-related differences in the clinical presentation of food-induced anaphylaxis. $J$ Pediatr. 2011;158(2):326-328. doi:10.1016/j. jpeds.2010.10.017

11. Dyer AA, Lau CH, Smith TL, Smith BM, Gupta RS. Pediatric emergency department visits and hospitalizations due to food-induced anaphylaxis in Illinois. Ann Allergy Asthma Immunol. 2015;115(1):56-62. doi:10.1016/j.anai.2015.05.006

12. Du Toit G, Roberts G, Sayre PH, et al. Randomized trial of peanut consumption in infants at risk for peanut allergy. $N$ Engl $J$ Med. 2015;372(9):803-813. doi:10.1056/NEJMoa1414850

13. Togias A, Cooper SF, Acebal ML, et al. Addendum guidelines for the prevention of peanut allergy in the United States: report of the National Institute of Allergy and Infectious Diseases-sponsored expert panel. Ann Allergy Asthma Immunol. 2017;118(2):166-173 e7. doi:10.1016/j.anai.2016.10.004 
14. Sampson HA, Munoz-Furlong A, Campbell RL, et al. Second symposium on the definition and management of anaphylaxis: summary report--Second National Institute of Allergy and Infectious Disease/ Food Allergy and Anaphylaxis Network symposium. J Allergy Clin Immunol. 2006;117(2):391-397. doi:10.1016/j.jaci.2005.12.1303

15. Gupta RS, Springston EE, Warrier MR, et al. The prevalence, severity, and distribution of childhood food allergy in the United States. Pediatrics. 2011;128(1):e9-17. doi:10.1542/peds.2011-0204

16. Vetander M, Helander D, Flodström C, et al. Anaphylaxis and reactions to foods in children--a population-based case study of emergency department visits. Clin Exp Allergy. 2012;42(4):568-577. doi:10.1111/j.1365-2222.2011.03954.x

17. Kahveci M, Akarsu A, Koken G, Sahiner UM, Soyer O, Sekerel BE. Food-induced anaphylaxis in infants, as compared to toddlers and preschool children in Turkey. Pediatr Allergy Immunol. 2020;31 (8):954-961. doi:10.1111/pai.13320

18. Simons FE, Sampson HA. Anaphylaxis: unique aspects of clinical diagnosis and management in infants (birth to age 2 years). J Allergy Clin Immunol. 2015;135(5):1125-1131. doi:10.1016/j. jaci.2014.09.014

19. Kimata H. Latex allergy in infants younger than 1 year. Clin Exp Allergy. 2004;34(12):1910-1915. doi:10.1111/j.13652222.2004.02128.x

20. Hogan MB, Kelly MA, Wilson NW. Idiopathic anaphylaxis in children. Ann Allergy Asthma Immunol. 1998;81(2):140-142. doi:10.1016/S1081-1206(10)62800-1

21. Pouessel G, Jean-Bart C, Deschildre A, et al. Food-induced anaphylaxis in infancy compared to preschool age: a retrospective analysis. Clin Exp Allergy. 2020;50(1):74-81. doi:10.1111/cea.13519

22. Simons FE. Anaphylaxis in infants: can recognition and management be improved?. J Allergy Clin Immunol. 2007;120(3):537-540. doi:10.1016/j.jaci.2007.06.025

23. Huang F, Chawla K, Järvinen KM, Nowak-Węgrzyn A. Anaphylaxis in a New York City pediatric emergency department: triggers, treatments, and outcomes. J Allergy Clin Immunol. 2012;129(1):162-8. e1-3. doi:10.1016/j.jaci.2011.09.018

24. Wolbing F, Fischer J, Koberle M, Kaesler S, Biedermann T. About the role and underlying mechanisms of cofactors in anaphylaxis. Allergy. 2013;68(9):1085-1092. doi:10.1111/all.12193

25. Chan JCK, Peters RL, Koplin JJ, et al. Food challenge and community-reported reaction profiles in food-allergic children aged 1 and 4 years: a population-based study. J Allergy Clin Immunol Pract. 2017;5(2):398-409e3. doi:10.1016/j.jaip.2016.12.021

26. Pistiner M, Mendez-Reyes JE, Eftekhari S, et al. Caregiver-reported presentation of severe food-induced allergic reactions in infants and toddlers. J Allergy Clin Immunol Pract. 2021;9(1):311-320 e2. doi:10.1016/j.jaip.2020.11.005

27. Simons FE, Ardusso LR, Bilo MB, et al. 2012 Update: World Allergy Organization Guidelines for the assessment and management of anaphylaxis. Curr Opin Allergy Clin Immunol. 2012;12(4):389-399. doi:10.1097/ACI.0b013e328355b7e4
28. Simons FE, Ebisawa M, Sanchez-Borges M, et al. 2015 update of the evidence base: World Allergy Organization anaphylaxis guidelines. World Allergy Organ J. 2015;8(1):32. doi:10.1186/s40413-015-0080-1

29. Lieberman P, Nicklas RA, Randolph C, et al. Anaphylaxis-a practice parameter update 2015. Ann Allergy Asthma Immunol. 2015;115 (5):341-384. doi:10.1016/j.anai.2015.07.019

30. Wright CD, Longjohn M, Lieberman PL, Lieberman JA. An analysis of anaphylaxis cases at a single pediatric emergency department during a 1-year period. Ann Allergy Asthma Immunol. 2017;118 (4):461-464. doi:10.1016/j.anai.2017.02.002

31. Robinson M, Greenhawt M, Stukus DR. Factors associated with epinephrine administration for anaphylaxis in children before arrival to the emergency department. Ann Allergy Asthma Immunol. 2017;119(2):164-169. doi:10.1016/j.anai.2017.06.001

32. Sidhu N, Jones S, Perry T, et al. Evaluation of anaphylaxis management in a pediatric emergency department. Pediatr Emerg Care. 2016;32(8):508-513. doi:10.1097/pec.0000000000000864

33. Chad L, Ben-Shoshan M, Asai Y, et al. A majority of parents of children with peanut allergy fear using the epinephrine auto-injector. Allergy. 2013;68(12):1605-1609. doi:10.1111/all.12262

34. Craig-Brangan KJ, Day MP. Update: 2017/2018 AHA BLS, ACLS, and PALS guidelines. Nursing. 2019;49(2):46-49. doi:10.1097/01. NURSE.0000552705.65749.a0

35. Sicherer SH, Simons FE. Self-injectable epinephrine for first-aid management of anaphylaxis. Pediatrics. 2007;119(3):638-646. doi:10.1542/peds.2006-3689

36. Brown JC. Epinephrine, auto-injectors, and anaphylaxis: challenges of dose, depth, and device. Ann Allergy Asthma Immunol. 2018;121 (1):53-60. doi:10.1016/j.anai.2018.05.001

37. Dreborg S, Kim H. Epinephrine autoinjectors: the needle length matters. Ann Allergy Asthma Immunol. 2020;124(5):449-450. doi:10.1016/j.anai.2019.12.014

38. Kim L, Nevis IF, Tsai G, et al. Children under $15 \mathrm{~kg}$ with food allergy may be at risk of having epinephrine auto-injectors administered into bone. Allergy Asthma Clin Immunol. 2014;10(1):40. doi:10.1186/1710-1492-10-40

39. Kim H, Dinakar C, McInnis P, et al. Inadequacy of current pediatric epinephrine autoinjector needle length for use in infants and toddlers. Ann Allergy Asthma Immunol. 2017;118(6):719-725 e1. doi:10.1016/ j.anai.2017.03.017

40. Dreborg S, Wen X, Kim L, et al. Do epinephrine auto-injectors have an unsuitable needle length in children and adolescents at risk for anaphylaxis from food allergy? Allergy Asthma Clin Immunol. 2016;12:11. doi:10.1186/s13223-016-0110-8

41. Prevention CfDCa. Voluntary Guidelines for Managing Food Allergies in Schools and Early Care and Education Programs. US Department of Health and Human Services; 2013.

42. Wang J, Bingemann T, Russell AF, Young MC, Sicherer SH. The allergist's role in anaphylaxis and food allergy management in the school and childcare setting. J Allergy Clin Immunol Pract. 2018;6 (2):427-435. doi:10.1016/j.jaip.2017.11.022

\section{Publish your work in this journal}

The Journal of Asthma and Allergy is an international, peer-reviewed open-access journal publishing original research, reports, editorials and commentaries on the following topics: Asthma; Pulmonary physiology; Asthma related clinical health; Clinical immunology and the immunological basis of disease; Pharmacological interventions and

Submit your manuscript here: https://www.dovepress.com/journal-of-asthma-and-allergy-journal new therapies. The manuscript management system is completely online and includes a very quick and fair peer-review system, which is all easy to use. Visit http://www.dovepress.com/testimonials.php to read real quotes from published authors. 